\title{
Pengenalan Batik Indonesia Menggunakan Ciri Warna dan Tekstur
}

\author{
Ema Rachmawati ${ }^{\star}$, Maula IIma Ahgnia Dwi Anjani, Febryanti Sthevanie \\ Fakultas Informatika, Universitas Telkom \\ *emarachmawati@telkomuniversity.ac.id
}

\section{Info Artikel}

\section{Kata Kunci :}

Batik, motif, Gray Level Cooccurrence Matrix, Color Difference Histogram, pengenalan batik

\section{Keywords :}

Batik, motifs, Gray Level Cooccurrence Matrix, Color Difference Histogram, batik recognition

\section{Tanggal Artikel}

Dikirim : 12 Mei 2020

Direvisi : 25 Mei 2020

Diterima : 30 Mei 2020

\begin{abstract}
Abstrak
Upaya pelestarian budaya bangsa melalui pengenalan batik merupakan hal yang harus selalu ditingkatkan. Terlebih dengan diakuinya budaya batik Indonesia oleh UNESCO sebagai bagian dari warisan budaya tak berwujud (intangible). Hal inilah yang mendasari dilakukannya sejumlah penelitian terkait pengenalan batik. Hasil kinerja yang sangat baik telah dicapai oleh berbagai sistem pengenalan batik. Namun, berbagai penelitian yang dilakukan tersebut masih terbatas pada jumlah motif batik yang sedikit. Oleh karena itu, pada penelitian ini dibangun sistem pengenalan batik dengan menggunakan 114 motif batik dari 14 daerah di propinsi Jawa Barat. Ciri gabungan dibangun dengan mengkombinasikan ciri tekstur dan warna. Ciri tekstur didapatkan dari Gray Level Co-occurrence Matrix (GLCM) sedangkan ciri warna didapatkan dari Color Difference Histogram (CDH). Penulis juga menambahkan variasi dalam dataset yang berupa rotate dan flip untuk memperbesar variasi intraclass. Hasil utama dari kinerja sistem yang dibuat adalah akurasi sebesar 99,128 \% dan F1-Score sebesar 98,9999\% pada pengenalan batik berdasarkan daerah, sedangkan pada pengenalan batik berdasarkan motif didapatkan akurasi sebesar 98,2456\% dan F1-Score sebesar 98,3208\%.
\end{abstract}

\begin{abstract}
The efforts to preserve the nation's culture through the introduction of batik are things that must always be improved, especially with the recognition of Indonesian batik culture by UNESCO as part of intangible cultural heritage. This is what underlies several studies related to batik recognition. Excellent performance results have been achieved by various batik recognition systems. However, various studies conducted are still limited to the small number of batik motifs. Therefore, this research developed a batik recognition system using 114 batik motifs from 14 regions in West Java province. Combined features are built by combining the features of texture and color. Texture features are obtained from the Gray Level Co-occurrence Matrix (GLCM), while the color features are obtained from the Color Difference Histogram (CDH). We also add variations in the dataset in the form of rotate and flip to enlarge intra-class variations. Our system performance achieves an accuracy of $99.128 \%$ and an F1-Score of $98.99 \%$ in the batik recognition of based on region. In contrast, in the batik recognition based on motifs, we obtained an accuracy of $98.25 \%$ and an F1-Score of $98.32 \%$.
\end{abstract}

\section{PENDAHULUAN}

Sejak tahun 2009 batik diakui secara resmi oleh UNESCO (United Nations Educational, Scientific and Cultural Oraganization). Departemen Budaya dan Pariwisata menyatakan bahwa Batik Indonesia masuk dalam UNESCO Respresentative List of Intangible Cultural Heritage of Humanity, yang merupakan pengakuan internasional terhadap salah satu mata budaya Indonesia [1]. Batik adalah karya bangsa yang menyimpan nilai leluhur Indonesia dan diakui oleh bangsa lain. Namun, minat terhadap pemahaman batik itu sendiri masih kurang. Salah satunya adalah pengenalan terhadap batik Indonesia. Sering kali kita melihat pemakai batik, tetapi kita tidak mengetahui nama motif batik yang digunakan dan/atau asal batik tersebut. 
Untuk terus melestarikan karya bangsa, kita harus mengenali budaya bangsa, salah satunya adalah batik. Oleh karena itu, diperlukan sistem yang dapat memberikan informasi terkait motif dan asal daerah batik. Jika dilihat dari perkembangan teknologi dan kebiasaan masyarakat yang ingin lebih praktis, ketika ingin mendapatkan suatu informasi yang tidak diketahui, maka masyarakat cenderung mencari dengan menggunakan media daring. Oleh karena itu diperlukan sistem yang dapat membantu masyarakat dalam mengenali batik.

Sejumlah penelitian telah dilakukan untuk mengenali jenis-jenis batik antara lain [2]-[11]. Minarno dan Suciati [2] melakukan eksperimen untuk mengetahui penggunaan ciri yang menghasilkan akurasi terbaik. Color Difference (CDH) dan Gray Level Co-ocurrence Matrix (GLCM) digunakan untuk mendapatkan ciri warna dan tekstur. Penelitian menghasilkan nilai precision sebesar 96,50\% menggunakan ciri gabungan. Sementara, Minarno dkk [3] mengklasifikasi motif batik menggunakan Multi Texton Histogram (MTH). K-Nearest Neighbor (KNN) dan Support Vector Machine (SVM) digunakan sebagai metode klasifikasi. Akurasi optimal didapatkan pada penggunaan KNN dengan k=5 dan MTH dengan 6 texton sebesar 82\%. Sementara, akurasi dari penggunaan SVM dan MTH dengan 6 texton sebesar $76 \%$.

Pada penelitian yang dilakukan oleh Sunawar [4] didapatkan hasil bahwa klasifikasi SVM lebih baik dibandingkan KNN dengan akurasi 78,3\% untuk k-NN dan 92,3\% untuk SVM, pada skenario eksperimen yang menggunakan cross-validation. Sementara pada skenario pembagian data (latih-uji) nilai akurasi yang didapatkan pada penggunaan KNN sebesar $67 \%$ dan $86 \%$ untuk SVM.

Gultom dkk [5] menggunakan 5 (lima) kelas batikyaitu Ceplok, Kawung, Lereng, Nitik,dan Parang pada sistem klasifikasi citra batik. Jumlah citra yang digunakan adalah 603 citra. Akurasi tertinggi sebesar 89\% dengan menggunakan ConvNet. Wicaksono dkk [6] menggunakan 11 kelas batik dari 7112 citra batik dengan ukuran 256x256 piksel. Mengusulkan arsitektur baru, yaitu IncRes, yang merupakan gabungan dari arsitektur GoogLeNet dan Residual Network. Akurasiyang didapatkan adalah 70,84\%. Minarno dkk [7] menggunakan Multi Texton Co-occurrence Descriptor(MTCD) dengan SVM dan Logistic Regression sebagai classifier. Sholihin [8] menggunakan 120 citra dari 3 (tiga) kelas batik, yaitu slempang, pethetan dan putihan. Menggunakan GLCM dan KNN, sistem yang dibangun berhasil mendapatkan akurasi yang sangat baik, yaitu 90,4\% pada $\mathrm{k}=6$. Vector ciri yang digunakan berukuran 21 dimensi, yang terdiri atas ciri warna (color moment) berjumlah 9 dimensi, ciri tekstur (GLCM) berjumlah 4 dimensi, dan ciri shape (Moment) berjumlah 7 dimensi.

Fahrizal dkk [9] melakukan klasifikasi pada 10 kelas Batik Banten menggunakan 300 citra (200 sebagai citra latih, dan 100 sebagai citra uji). Akurasi yang didapatkan yaitu 98\% dengan menggunakan metode GLCM dan Neural Network. Andrian dkk [10] melakukan klasifikasi pada 4 (empat) kelas batik Lampung (Jung Agung, Siger Kembang Cengkih, Siger Ratu Agung, dan Sembagi) menggunakan GLCM dan KNN. Akurasi tertinggi yang berhasil didapat adalah 97,96\% untuk k=7 dan sudut=135. Kelas negatif yang digunakan pada klasifikasi yaitu batik Jawa Parang Kusumo dan Batik Jawa Parang Rusak. Rasyidi dan Bariyah [11] melakukan klasifikasi pada 6 (enam) kelas batik, yaitu Banji, Ceplok, Kawung, Mega Mendung, Parang, dan Sekar Jagad, dengan total 994 citra. Dengan menggunakan ConvNet sistem yang dibangun berhasil mencapai akurasi sebesar $94 \%$.

Secara umum dapat dilihat bahwa sejumlah penelitian pengenalan batik yang telah dilakukan mampu menghasilkan kinerja sistem yang sangat baik dengan, terutama dengan menggunakan ciri warna dan tekstur. Namun jumlah kelas batik yang diteliti pada sejumlah eksperimen tersebut masih relatif sedikit, paling banyakhanya 11 kelas. Berdasarkan survei yang dilakukan oleh Zhang dkk [12], salah satu tantangan pada sistem klasifikasi terletak pada semakin besarnya jumlah kelas dari kategori (kelas) berbeda, semakin besarnya variasi intra-class, dan semakin kecilnya perbedaan visual inter-class.

Oleh karena itu, pada penelitian ini dibangun kumpulan data batik yang terdiri atas 114 kelas (motif) dari 14 daerah di Jawa Barat. Variasi intra-class ditingkatkan dengan menambahkan citra yang telah dibalik (flip) dan diputar (rotate) pada tiap citra di tiap motif. Akurasi sebesar 98,25\% didapatkan pada hasil klasifikasi 114 motif batik dengan F1-score sebesar 98,32\% menggunakan ciri gabungan dari ciri warna dan tekstur pada classifier Support Vector Machine(SVM).

\section{METODE PENELITIAN}

Sistem pengenalan batik yang dibangun pada penelitian ini terdiri atas dua skema, yaitu pelatihan dan pengujian. Pada skema pelatihan (Gambar 1) sistem melatih vektor ciri yang dihasilkan dari proses ekstraksi ciri yang selanjutnya disimpan dalam model. Metode klasifikasi yang digunakan pada tahap pelatihan adalah Support Vector Machine (SVM) dengan metode ekstraksi ciri warna yang digunakan adalah Color Difference Histogram (CDH) dan ekstraksi ciri tekstur menggunakan Gray Level Co-occurrence Matrix (GLCM). Model yang dihasilkan pada skema pelatihan selanjutnya digunakan pada skema pengujian (Gambar 2) untuk mengetahui kinerja sistem pengenalan batik secara keseluruhan. 


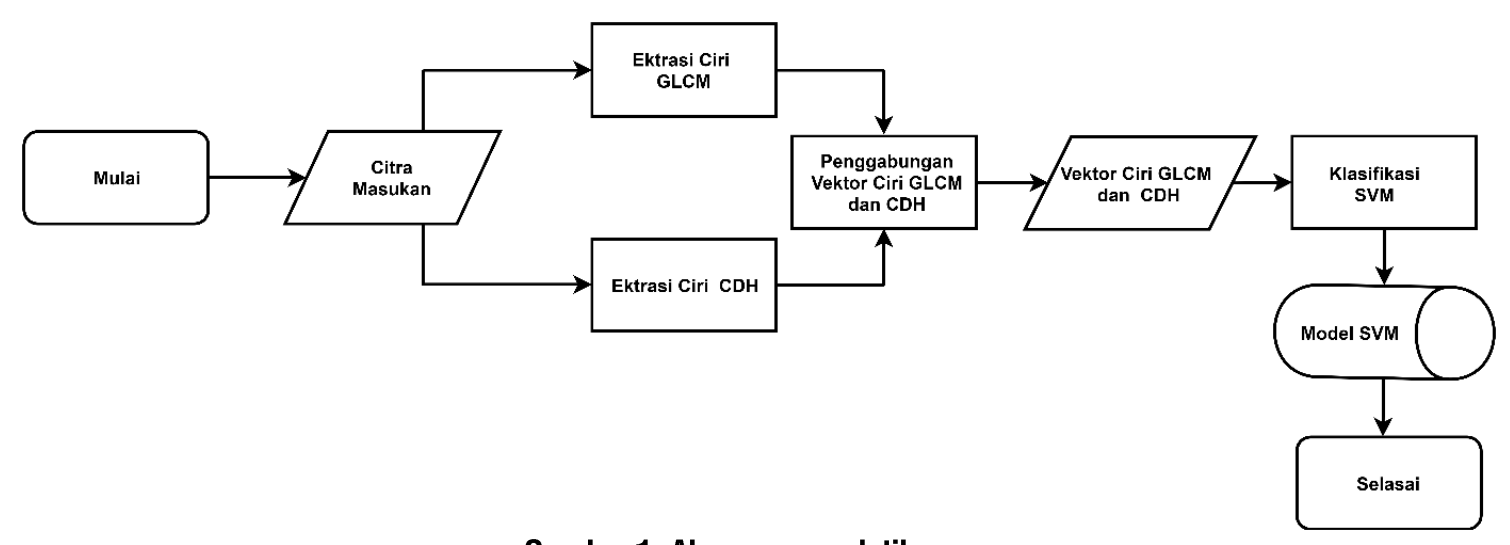

Gambar 1. Alur proses pelatihan

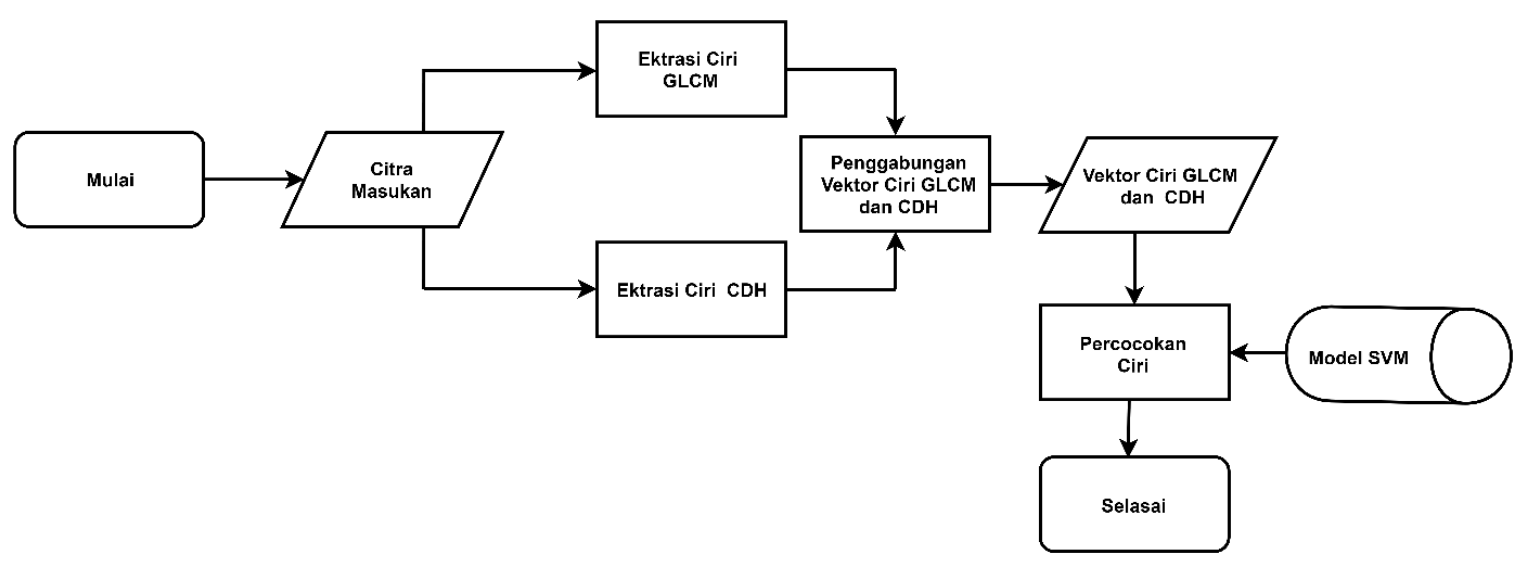

Gambar 2. Alur proses pengujian

\subsection{Ekstraksi Ciri}

Vektor ciri warna dan tekstur digabungkan ke dalam satu vektor ciri gabungan yang digunakan sebagai vektor ciri dari tiap citra batik (Gambar 3). Ciri tekstur yang digunakan adalah GLCM, sedangkan ciri warna yang digunakan adalah CDH. Pada Subbagian 2.1.1 dipaparkan mekanisme ekstraksi ciri tekstur, sedangkan pada Subbagian 2.1.2 dipaparkan ekstraksi ciri warna. 


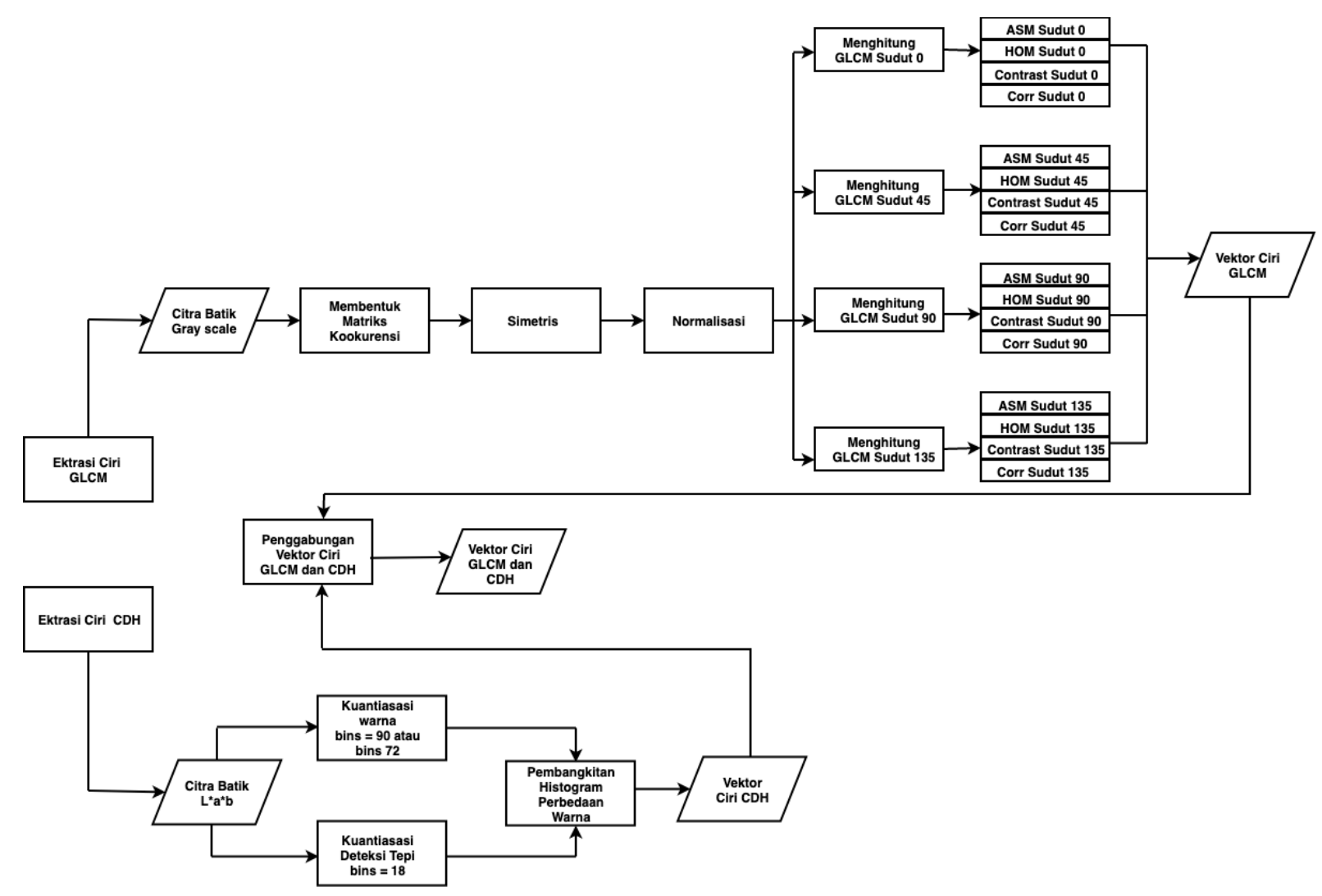

Gambar 3. Diagram proses ekstraksi ciri GLCM dan CDH

\subsubsection{Ciri Tekstur: Gray Level Co-occurrence Matrix (GLCM)}

GLCM merupakan metode yang paling banyak digunakan dalam teknis analisis tekstur [13]. GLCM mengidentifikasi seberapa sering kombinasi yang berbeda pada nilai keabuan yang muncul pada citra. Secara umum cara kerja ekstraksi ciri tekstur menggunakan GLCM adalah sebagai berikut [14].

1) Citra warna diubah ke dalam citra keabuan untuk keperluan pembentukan matriks kookurensi.

2) Matriks kookurensi merupakan matriks yang menyimpan jumlah kemunculan nilai keabuan yang bersamaan, yaitu jumlah kejadian satu level nilai intensitas piksel yang bertetangga dengan satu level intensitas piksel lain dalam jarak (d) dan orientasi sudut $(\theta)$ tertentu. Jarak dinyatakan dalam piksel dan orientasi dinyatakan dalam derajat. Orientasi dibentuk dalam empat arah sudut dengan interval sudut $45^{\circ}$, yaitu $0^{\circ}, 45^{\circ}, 90^{\circ}$, dan $135^{\circ}$.

3) GLCM harus berupa matriks simetris, yaitu simetris di sekitar diagonal. Artinya, nilai piksel yang sama akan muncul pada sel yang berlawanan sisi dengan diagonal.

4) Nilai probabilitas dihitung pada tahap normalisasi, yaitu dengan membagi jumlah kemunculan ketetanggaan piksel tertentu dengan jumlah seluruh piksel ketetanggaan yang mungkin muncul. Misalkan jika terdapat hubungan ketetanggaan antara piksel $(2,2)$ yang sangat mirip dengan hubungan ketetanggaan piksel $(2,3)$. Kemunculan dari piksel $(2,2)$ adalah 6 kali dari 24 kombinasi horisontal, sedangkan piksel $(2,3)$ hanya satu kali. Proses normalisasi akan membedakan piksel $(2,2)$ dan $(2,3)$ yang mirip tersebut dengan cara membagi kemunculan piksel dengan jumlah kemungkinan piksel yang muncul. Piksel $(2,2)$ memiliki angka kemungkinan muncul 0,25 sedangkan piksel $(2,3)$ sebesar 0,0042.

5) Ekstraksi ciri tekstur, yaitu energi (Angular Second Moment-ASM), Homogeneity (HOM), Contrast (CON), dan Correlation (CORR). Energi merupakan reperesentasi homogenitas citra. Saat nilai energi tinggi, hubungan homogenitas akan meningkat. Homogeneity untuk mengukur homogenitas. Kontras adalah tingkat variasi abu-abu, jika citra bertekstur halus artinya memiliki nilai kontras rendah, sedangkan jika citra memiliki tekstur yang kasar artinya 
nilai kontras tinggi. Korelasi adalah hubungan linear antar piksel. Ciri energi, homogeneity, kontras dan korelasi dihitung dengan persamaan (1), (2), (3), dan (4).

$$
\begin{aligned}
& \text { ASM }=\sum_{i, j=0}^{L-1} P(i, j, d, \theta)^{2} \\
& \text { HOM }=\sum_{i, j=0}^{L-1} \frac{P(i, j, d, \theta)}{1+(i-j)^{2}} \\
& \text { CON }=\sum_{i, j=0}^{L-1}(i-j)^{2} \cdot P(i, j, d, \theta) \\
& \text { CORR }=\sum_{i, j=0}^{L-1} \frac{\left(i-\mu_{x}\right)\left(j-\mu_{y}\right) P(i, j, d, \theta)}{\sigma x \sigma y} \\
& \text { dengan } \mu_{x}=\sum_{i, i=0}^{L-1} i . P(i, j, d, \theta), \mu_{y}=\sum_{i, i=0}^{L-1} i . P(i, j, d, \theta), \\
& \sigma_{x}=\sum_{i, j=0}^{L-1}\left(i-\mu_{x}\right)^{2} \cdot P(i, j, d, \theta), \sigma_{y}=\sum_{i, j=0}^{L-1}\left(j-\mu_{Y}\right)^{2} \cdot P(i, j, d, \theta) .
\end{aligned}
$$

Untuk mendeteksi kookurensi, setiap ciri dihitung dengan jarak satu piksel pada empat titik arah, yaitu $0^{\circ}, 45^{\circ}, 90^{\circ}$, dan $135^{\circ}$. Ukuran matriks adalah $L x L$. $P$ adalah probabilitas dari piksel $i$ yang bertetangga dengan piksel $j$ dalam jarak $d$ dan orientasi tepi $\theta$. Ciri GLCM dengan $\operatorname{Hasm}(\theta)$, Hhom $(\theta), H \operatorname{cont}(\theta), H \operatorname{corr}(\theta)$ dengan $\theta$ adalah $0^{\circ}, 45^{\circ}, 90^{\circ}$, dan $135^{\circ}$ dilambangkan dengan (5).

$$
\operatorname{Hglcm}=\left[\operatorname{Hasm}\left(0^{\circ}\right) . . \operatorname{Hasm}\left(135^{\circ}\right), \operatorname{Hhom}\left(0^{\circ}\right) . . H h o m\left(135^{\circ}\right), H \operatorname{cont}\left(0^{\circ}\right) . . H \operatorname{Hont}\left(135^{\circ}\right), H \operatorname{Horr}\left(0^{\circ}\right) . . H \operatorname{corr}\left(135^{\circ}\right)\right]
$$

\subsubsection{Ekstraksi Ciri Warna: Color Difference Histogram (CDH)}

Color Difference Histogram (CDH) merupakan modifikasi dari microstructure descriptor (MSD) yang diperoleh dari color difference ke edge-map dan orientasi tepi ke warna [2]. Proses ekstraksi ciri pada $\mathrm{CDH}$ adalah sebagai berikut.

1) Merubah citra RGB ke ruang warna $L^{*} a^{*} b^{*}$.

2) Deteksi orientasi tepi pada ruang warna $L^{*} a^{\star} b^{\star}$. Pada bagian ini orientasi tepi memainkan peran penting dan dapat mempengaruhi persepsi citra manusia. Bagian ini juga dapat mendeskripsikan batas-batas objek dan memberikan informasi semantik dari suatu citra, mewakili ciri tekstur dan bentuk secara bersamaan. Pada penelitian ini orientasi tepi dihitung untuk setiap komponen $L$ * $a$ * $b$ *. Deteksi orientasi tepi biasanya dimulai dengan mengubah citra ke grayscale. Tetapi, dalam metode ini akan kehilangan sejumlah informasi kromatik. Untuk mencegah hilangnya informasi kromatik, digunakan metode Zenzo [15] untuk mendapatkan gradien dari citra warna. Pada bagian ini, setiap komponen $\mathrm{L}$ * $\mathrm{a}$ * $\mathrm{b}$ * dideteksi dengan orientasi horisontal ( $g x \mathrm{x}$ ) dan orientasi vertikal (gyy), kemudian dot product dihitung dari gxx dan gyy menghasilkan gxy, menggunakan operator Sobel. Setelah itu, gradien yang terdiri dari komponen magnitude dan arah. Untuk mendapatkan tingkat perubahan orientasi gradien yang maksimum, rumus yang digunakan adalah (6),

$$
\varphi(x, y)=\frac{1}{2} \arctan \left(\frac{2 g x y}{g x x-g y y}\right)
$$

dengan tingkat perubahan orientasi untuk $\phi(\mathrm{x}, \mathrm{y})$ menggunakan persamaan (7) dan (8).

$$
\begin{aligned}
& G 1(x, y)=\left\{\frac{1}{2}[(g x x+g y y)+(g x x-g y y) \cos 2 \varphi+2 g x y \sin 2 \varphi]\right\}^{1 / 2} \\
& G 2(x, y)=\left\{\frac{1}{2}\left[(g x x+g y y)+(g x x-g y y) \cos 2\left(\varphi+\frac{\pi}{2} 2 g x y \sin 2\left(\varphi+\frac{\mu}{2}\right)\right)\right]\right\}^{1 / 2}
\end{aligned}
$$

Selain itu, dibutuhkan nilai maksimum dari gradient $(F \max )$

$$
F \max =\max (G 1, G 2) \quad \text { dengan }: \varphi= \begin{cases}\varphi & \text { if } F \max =G 1(x, y) \\ \varphi+\frac{\pi}{2} & \text { if } F \max =G 2(x, y)\end{cases}
$$

Ukuran interval untuk setiap bin dihitung dengan membagi 360 dengan $m$. Misalkan untuk $m=6$ maka ukuran intervalnya adalah 60 , sehingga semua orientasi tepi dikuantisasi secara bersamaan dengan interval $0,60,120,180$, 240, dan 300 . 
3) Kuantisasi ruang warna $L^{*} a^{*} b^{*}$. Setiap komponen dalam $L$ * $a *{ }^{*}$ * dikuantisasi menjadi $n-b i n$, dengan $n=\{54$, $63,72,81,90\}$. Untuk citra berwarna ukuran $M \times N$, jika $\mathrm{n}=72$ maka $\mathrm{L}=8,{ }^{*} \mathrm{a}=3,{ }^{*} \mathrm{~b}=3$. Maka dapat menunjukan bahwa $C(x, y)$ citra terkuantisasi dengan $0<x<M, 0<y<N$.

4) Pembangkitan $\mathrm{CDH}$. $\mathrm{CDH}$ dibangkitkan dari kuantisasi warna dan kuantisasi tepi tiap piksel, yaitu $\mathrm{C}(\mathrm{x}, \mathrm{y})$, dengan representasi nilai $w \in 0,1, \ldots, w-1$, dan $\theta(x, y)$, dengan representasi nilai $v=\in 0,1, \ldots, v-1$. CDH mengacu pada hubungan piksel pada lokasi $(x, y)$ dan lokasi tetangganya $\left(x^{\prime}, y^{\prime}\right)$ sejauh $D$. Sehingga kuantisasi tiap warna dan tepi piksel tetangga masing-masing adalah $C\left(x^{\prime}, y^{\prime}\right)$ dan $\theta\left(x^{\prime}, y^{\prime}\right)$. Perhitungan untuk $\mathrm{CDH}$ berdasarkan kuantisasi warna dapat dilihat pada persamaan (11), sedangkan untuk kuantisasi tepi dapat dilihat pada persamaan (12). Kemudian hasil perhitungan yang didapatkan dari tiap kuantisasi warna dan kuantisasi tepi digabungkan menjadi vektor ciri $H c d h$ dengan persamaan (13). Vektor ciri yang dihasilkan adalah vektor dengan dimensi $W+V$.

$$
\begin{aligned}
& \text { Hcolor }(C(x, y))=\left\{\begin{array}{c}
\sum \sqrt{(\Delta L)^{2}+\left(\Delta a^{2}\right)+\left(\Delta b^{2}\right)} \\
\text { where } \theta(x, y)=\theta\left(x^{\prime}, y^{\prime}\right) ; \max \left(\left|x-x^{\prime}\right|\right),\left(\left|y-y^{\prime}\right|\right)=D
\end{array}\right. \\
& \operatorname{Hori}(\theta(x, y))=\left\{\begin{array}{c}
\sum \sqrt{(\Delta L)^{2}+\left(\Delta a^{2}\right)+\left(\Delta b^{2}\right)} \\
\text { where } C(x, y)=C\left(x^{\prime}, y^{\prime}\right) ; \max \left(\left|x-x^{\prime}\right|\right),\left(\left|y-y^{\prime}\right|\right)=D
\end{array}\right. \\
& \text { Hcdh }=[\operatorname{Hcolor}(0), \text { Hcolor }(1) \ldots \text { Hcolor }(W-1), \text { Hori }(0), \text { Hori }(1) \ldots \text { Hori }(\text { V }-1)
\end{aligned}
$$

Misalnya jika dimensi kuantisasi warna $=72$ dan orientasi tepi $=18$, maka total dimensi ciri adalah $72+18=90$. $\mathrm{H}$ adalah notasi dari ciri tersebut.

Vektor ciri gabungan dari ciri CDH dan GLCM adalah sebagai berikut

$$
H=[\mathrm{Hcdh}, \mathrm{Hglcm}]
$$

Sebagai contoh, iika pada CDH digunakan kuantisasi warna $=72, L=8, a=3, b=3$, dan kuantisasi orientasi tepi $=18$, dan total ciri GLCM = 16, maka total ciri penggabungan ciri GLCM dan ciri CDH adalah 106 ciri.

\section{HASIL DAN PEMBAHASAN}

Pada bagian ini dijelaskan eksperimen yang dilakukan pada sistem pengenalan batik. Penjelasan dataset yang digunakan terdapat pada Subbagian 3.1, vektor ciri dijelaskan pada Subbagian 3.2, hasil pembangunan model dijelaskan pada Subbagian 3.3, hasil pengenalan batik berdasar daerah dijelaskan pada Subbagian 3.4, dan hasil pengenalan batik berdasar motif dijelaskan pada Subbagian 3.5.

\subsection{Dataset}

Citra yang digunakan pada penelitian ini adalah citra batik dari 14 daerah di Propinsi Jawa Barat yang terdaftar dalam Buku Saku Batik Jawa Barat [17]. Nama daerah beserta jumlah citra batik dari tiap daerah dapat dilihat pada Tabel 1, yaitu daerah Bandung, Bogor, Ciamis, Cimahi, Cirebon, Garut, Indramayu, Kabupaten Bandung, Kabupaten Cirebon, Kabupaten Tasikmalaya, Kuningan, Majalengka, Sumedang, dan Tasikmalaya.

Jumlah motif citra batik yang ada pada dataset adalah 114 motif. Untuk menambah variasi citra pada tiap kelas motif, dilakukan proses flip dan rotate pada tiap citra di tiap motif, sehingga total citra yang digunakan adalah 2052 citra dengan ukuran 128x128 piksel. Contoh hasil proses flip dan rotate dapat dilihat pada Gambar 4. Untuk keperluan eksperimen, citra dibagi ke dalam citra latih dan citra uji, dengan jumlah citra latih 1596 citra dan citra uji sebanyak 456 citra. Contoh citra pada 114 kelas motif dapat dilihat pada bagian Lampiran.

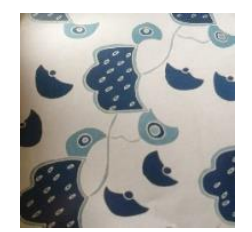

(a)

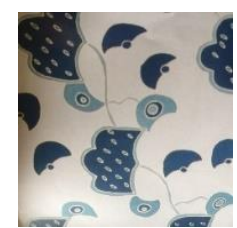

(b)

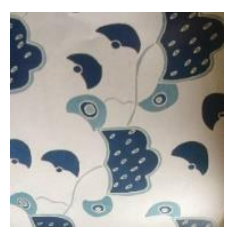

(c)

Gambar 4 Contoh dataset batik yang digunakan: (a) normal, (b) flip, (c) rotate 
Tabel 1. Jumlah citra batik dari tiap daerah

\begin{tabular}{lc}
\hline Daerah & Jumlah Citra \\
\hline Bandung & 180 \\
\hline Bogor & 108 \\
\hline Ciamis & 90 \\
\hline Cimahi & 180 \\
\hline Cirebon & 180 \\
\hline Garut & 162 \\
\hline Indramayu & 180 \\
\hline Kab. Bandung & 180 \\
\hline Kab. Cirebon & 180 \\
\hline Kab. Tasikmalaya & 162 \\
\hline Kuningan & 90 \\
\hline Majalengka & 36 \\
\hline Sumedang & 144 \\
\hline Tasikmalaya & 180 \\
\hline
\end{tabular}

\subsection{Ekstraksi Ciri Tekstur dan Warna}

Ekstrasi ciri tekstur pada penelitian ini menggunakan metode GLCM, yaitu ciri contrast, ASM, homogeneity, dan correlation pada empat arah, yaitu $0^{\circ}, 45^{\circ}, 90^{\circ}$, dan $135^{\circ}$. Ukuran vektor ciri tekstur dari GLCM ini adalah 16 dimensi.

Sementara itu, ekstraksi ciri warna dengan metode $\mathrm{CDH}$ akan menghasilkan vektor ciri yang merupakan penggabungan dari hasil dari kuantisasi warna dan kuantisasi tepi tiap piksel. Ukuran vektor ciri sangat bergantung pada nilai kuantisasi orientasi tepi dan nilai kuantisasi warna $L^{*} a^{*} b^{*}$. Misalkan kuantisasi orientasi tepi menggunakan bin=18 dan kuantisasi warna menggunakan dengan bin $L^{*}=10, a^{*}=3, b^{*}=3$, maka akan didapatkan vektor ciri warna berukuran 108 dimensi.

Vektor ciri gabungan didapatkan dengan melakukan konkatenasi pada vektor ciri tekstur dan warna yang telah didapatkan. Misal dari ekstraksi ciri tekstur didapatkan 16 ciri dan dari ekstraksi ciri warna didapatkan 108 ciri. Vektor ciri gabungan menjadi berukuran 124 dimensi.

\subsection{Pembangunan Model}

Pembangunan model dilakukan dengan melatih 1596 citra latih menggunakan SVM dengan 3 (tiga) kernel, yaitu linear, $\mathrm{RBF}$, dan polinomial. Model yang dibangun selanjutnya dievaluasi menggunakan $k$-fold cross-validationdengan $\mathrm{k}=10$ [18]. Pada eksperimen ini, terdapat 4 (empat) model yang dievaluasi, yaitu 2 (dua) model kelas batik berdasarkan daerah, dan 2 (dua) model kelas batik berdasarkan motif.

1. Model kelas batik berdasarkan daerah dengan vektor ciri tekstur 16 dimensi dan ciri warna 108 dimensi.

2. Model kelas batik berdasarkan daerah dengan vektor ciri tekstur 16 dimensi dan ciri warna 90 dimensi.

3. Model kelas batik berdasarkan motif dengan vektor ciri tekstur 16 dimensi dan ciri warna 108 dimensi.

4. Model kelas batik berdasarkan motif dengan vektor ciri tekstur 16 dimensi dan ciri warna 90 dimensi.

Akurasi 4 (empat) model yang dibangun dapat dilihat pada Tabel 2. Secara umum, kinerja model yang dibangun sangat baik dengan akurasi lebih dari $80 \%$. Akurasi terbaik untuk model kelas batik berdasarkan daerah didapatkan pada penggunaan kernel polinomial, sedangkan akurasi terbaik untuk model kelas batik berdasarkan motif didapatkan pada penggunaan kernel RBF.

Pada pengujian pembangunan model ini, model untuk kelas batik berdasarkan daerah yang mendapatkan akurasi terbaik adalah model yang menggunakan vektor ciri gabungan berukuran 124 dimensi ( 16 ciri GLCM dan 108 ciri CDH) dengan akurasi $98,56 \%$. Sementara, model terbaik untuk kelas batik berdasar motif didapatkan pada penggunaan vektor ciri gabungan berukuran 124 dimensi juga (16 ciri GLCM dan 108 ciri CDH) dengan akurasi 98,06\%. 
Tabel 2. Hasil akurasi pembangunan model

\begin{tabular}{|c|c|c|c|c|}
\hline \multirow{2}{*}{ Model Latih } & \multirow{2}{*}{$\begin{array}{c}\text { Dimensi Vektor } \\
\text { Ciri }\end{array}$} & \multicolumn{3}{|c|}{ Akurasi } \\
\hline & & Linear & $R B F$ & Polinomial \\
\hline \multirow{2}{*}{$\begin{array}{l}\text { Berdasarkan } \\
\text { daerah }\end{array}$} & $\begin{array}{l}\text { 1. } \mathrm{GLCM}=16 \\
\mathrm{CDH}=108\end{array}$ & $80,89 \%$ & $97,24 \%$ & $98.56 \%$ \\
\hline & 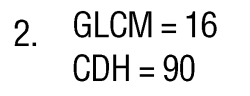 & $81,83 \%$ & $97,06 \%$ & $98,43 \%$ \\
\hline \multirow{2}{*}{$\begin{array}{l}\text { Berdasarkan } \\
\text { motif }\end{array}$} & $\begin{array}{l}\text { 3. } \mathrm{GLCM}=16 \\
\mathrm{CDH}=108\end{array}$ & $97,43 \%$ & $98,06 \%$ & $97,87 \%$ \\
\hline & $\begin{array}{l}\text { 4. } \mathrm{GLCM}=16 \\
\mathrm{CDH}=90\end{array}$ & $96,68 \%$ & $97,62 \%$ & $97,57 \%$ \\
\hline
\end{tabular}

\subsection{Pengenalan Batik Berdasar Daerah}

Pada bagian ini dipaparkan hasil pengujian pengenalan batik berdasarkan daerah menggunakan 456 citra. Terdapat 14 kelas (daerah) yang diklasifikasikan dengan menggunakan gabungan vektor ciri sebagai berikut:

1. 16 ciri GLCM dan 108 ciri CDH (90 dimensi dari kuantisasi warna ditambah dengan 18 dimensi dari orientasi tepi)

2. 16 ciri GLCM dan 90 ciri CDH (72 dimensi dari kuantisasi warna ditambah dengan 18 dimensi dari orientasi tepi)

Hasil dari pengujian kelas batik berdasarkan daerah menggunakan SVM sebagai classifier pada kernel linear, RBF, dan polynomial dapat dilihat pada Tabel 3 . Akurasi pengujian terbaik didapatkan pada penggunaan vektor ciri gabungan berdimensi 124 dengan kernel polinomial, dengan akurasi $99,12 \%$.

Tabel 3 Hasil pengujian pengenalan batik berdasarkan daerah

\begin{tabular}{|c|c|c|c|c|c|}
\hline \multirow{2}{*}{ Parameter } & \multirow{2}{*}{$\begin{array}{c}\text { Dimensi } \\
\text { Vektor Ciri }\end{array}$} & \multirow{2}{*}{$\begin{array}{c}\text { Dimensi } \\
\text { Vektor Ciri } \\
\text { Gabungan }\end{array}$} & \multicolumn{3}{|c|}{ Akurasi pengujian dengan model SVM } \\
\hline & & & Linear & $R B F$ & polynomial \\
\hline $\begin{array}{l}\text { GLCM , } D=1 \text {, offset. } \\
C D H, D=1 \text {, edge }=18 \\
\text { bin, } L=10 a=3 b=3\end{array}$ & $\begin{array}{l}\mathrm{GLCM}=16 \\
\mathrm{CDH}=108\end{array}$ & 124 & $80,70 \%$ & $96,05 \%$ & $99,12 \%$ \\
\hline $\begin{array}{l}\text { GLCM , } D=1 \text {, offset. } \\
C D H, D=1 \text {, edge }=18 \\
\text { bin, } L=8 a=3 b=3\end{array}$ & $\begin{array}{l}\mathrm{GLCM}=16 \\
\mathrm{CDH}=90\end{array}$ & 106 & $78,51 \%$ & $96,71 \%$ & $98,03 \%$ \\
\hline
\end{tabular}

Nilai precision, recall, dan F1-score pada pengenalan batik berdasar daerah menggunakan 124 ciri dan 106 ciri dapat dilihat pada Gambar 5 dan Gambar 6. Nilai precision terbaik didapatkan pada pengenalan batik menggunakan 124 ciri dengan SVM polinomial sebesar 98,75\%. Nilai recall dan F1-score pada penggunaan 124 ciri ini adalah 99,31\% dan 98,99\%. Sementara itu nilai precision terbaik pada pengenalan batik menggunakan 106 ciri dengan SVM polinomial sebesar $96,53 \%$. Nilai recall dan F1-score pada penggunaan 106 ciri ini adalah 98,39\% dan 97,31\%. Berdasarkan nilai F1-score, penggunaan 124 ciri pada pengenalan batik berdasarkan daerah mendapatkan hasil yang lebih baik jika dibandingkan penggunaan 106 ciri. 


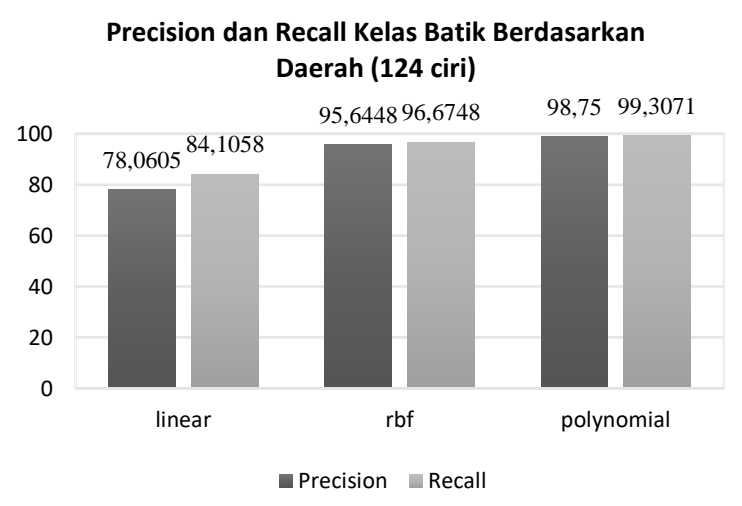

(a)

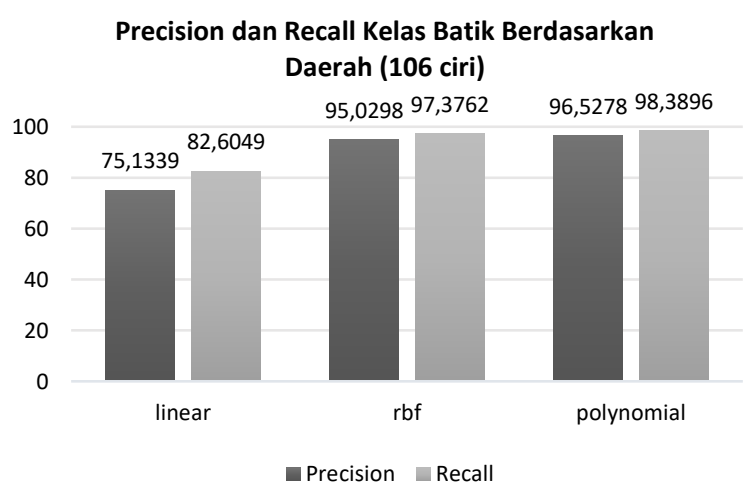

(b)

Gambar 5. Precision dan recall pengenalan batik berdasarkan daerah dengan menggunakan (a) 124 ciri dan (b) 106 ciri

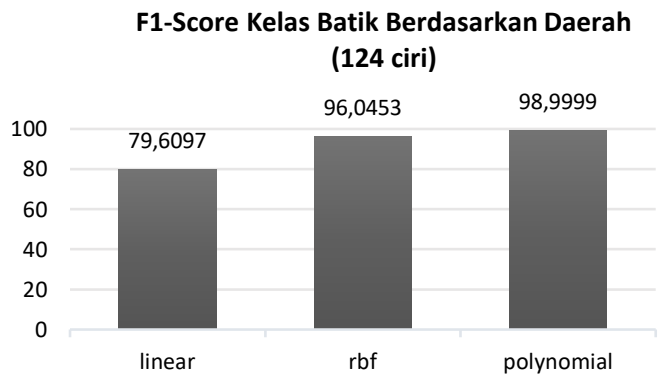

(a)

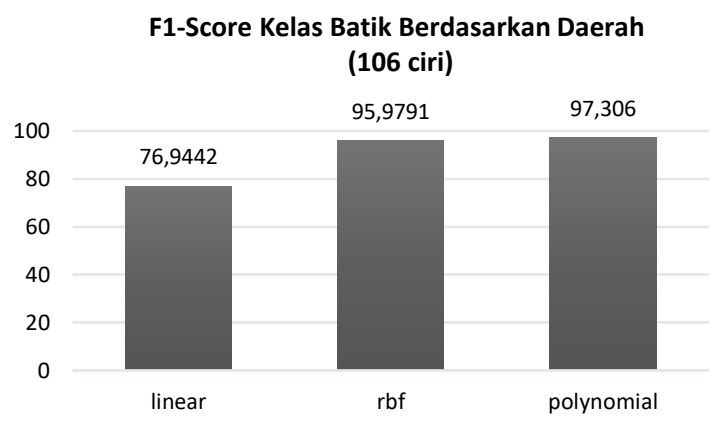

(b)

Gambar 6. F1-Score pengenalan batik berdasarkan daerah dengan menggunakan (a) 124 ciri dan (b) 106 ciri

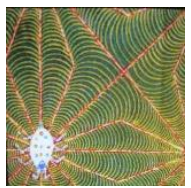

\section{Gambar 7. Kelas yang salah diklasifikasi pada pengenalan batik berdasarkan daerah}

Gambar 7 merupakan contoh citra yang salah diklasfikasi pada pengenalan citra berdasar daerah. Citra tersebut memiliki label kelas Garut, namun salah diklasifikasi sebagai kelas Cimahi.

\subsection{Pengenalan Batik Berdasar Motif}

Pada bagian ini dipaparkan hasil pengujian pengenalan batik berdasarkan motif menggunakan 456 citra uji. Terdapat 114 kelas (motif) yang harus diklasifikasikan dengan menggunakan gabungan vektor ciri sebagai berikut:

1. 16 ciri GLCM dan 108 ciri CDH (90 dimensi dari kuantisasi warna ditambah dengan 18 dimensi dari orientasi tepi)

2. 16 ciri GLCM dan 90 ciri CDH (72 dimensi dari kuantisasi warna ditambah dengan 18 dimensi dari orientasi tepi)

Hasil pengujian pengenalan batik berdasarkan motif menggunakan SVM sebagai classifier dengan kernel linear, RBF, dan polinomial dapat dilihat pada Tabel 4. Terlihat bahwa akurasi terbaik didapatkan pada penggunaan vektor ciri gabungan berdimensi 124 dengan kernel RBF dengan capaian akurasi sebesar 98,25\%. 
Tabel 4 Hasil pengujian pengenalan batik berdasarkan motif

\begin{tabular}{|c|c|c|c|c|c|}
\hline \multirow{2}{*}{ Parameter } & \multirow{2}{*}{$\begin{array}{c}\text { Dimensi Vektor } \\
\text { Ciri }\end{array}$} & \multirow{2}{*}{$\begin{array}{l}\text { Dimensi Vektor } \\
\text { Ciri Gabungan }\end{array}$} & \multicolumn{3}{|c|}{ Akurasi pengujian dengan model SVM } \\
\hline & & & Linear & $R B F$ & polinomial \\
\hline $\begin{array}{l}\text { GLCM , } D=1 \text {, offset. } \\
C D H, D=1 \text {, edge= } 18 \text { bin, } \\
L=9 a=3 b=3\end{array}$ & $\begin{array}{l}\mathrm{GLCM}=16 \\
\mathrm{CDH}=108\end{array}$ & 124 & $96,71 \%$ & $98,25 \%$ & $97,59 \%$ \\
\hline $\begin{array}{l}\text { GLCM , } D=1 \text {, offset. } \\
C D H, D=1 \text {, edge }=18 \text { bin, } \\
L=8 a=3 b=3\end{array}$ & $\begin{array}{l}\mathrm{GLCM}=16 \\
\mathrm{CDH}=90\end{array}$ & 106 & $95,18 \%$ & $98,03 \%$ & $96,27 \%$ \\
\hline
\end{tabular}

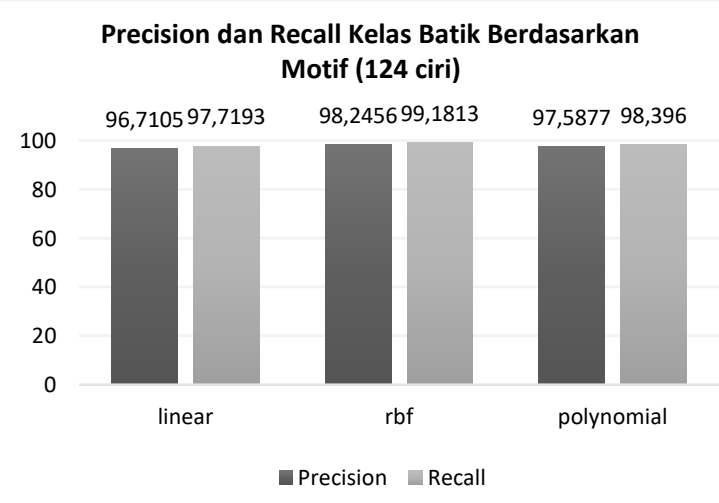

(a)

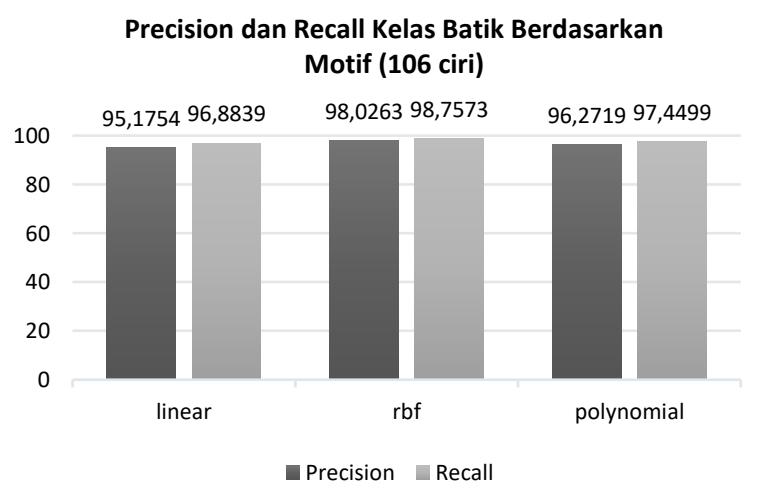

(b)

Gambar 8. Precision dan recallpengenalan batik berdasarkan motif menggunakan (a) 124 ciri dan (b) 106 ciri

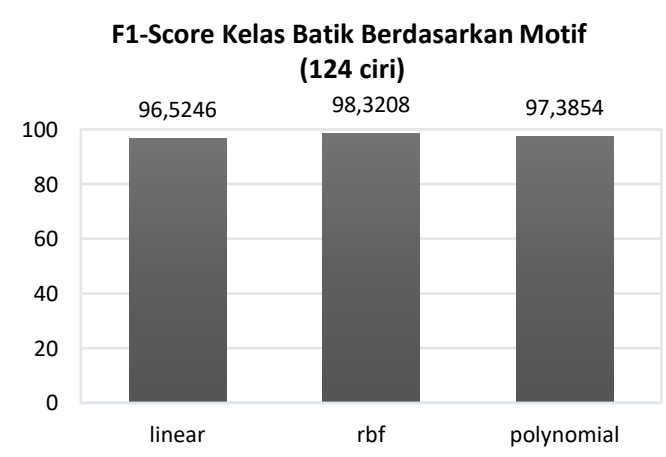

(a)

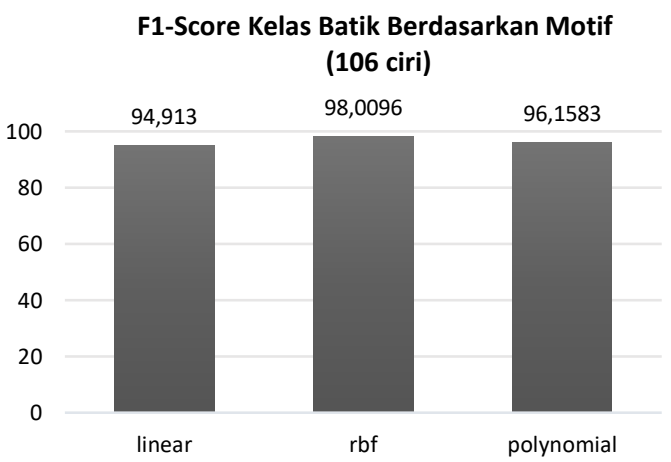

(b)

Gambar 9. F1-Score pengenalan batik berdasarkan motif menggunakan (a) 124 ciri dan (b) 106 ciri

Nilai precision, recall, dan F1-score pada pengenalan batik berdasar motif menggunakan 124 ciri dan 106 ciri dapat dilihat pada Gambar 8 dan Gambar 9. Nilai precision terbaik didapatkan pada pengenalan batik menggunakan 124 ciri dengan SVM RBF sebesar 98,25\%. Nilai recall dan F1-score pada penggunaan 124 ciri ini adalah 99,18\% dan 98,32\%. Sementara itu nilai precision terbaik pada pengenalan batik menggunakan 106 ciri dengan SVM RBF sebesar 96,03\%. Nilai recall dan F1-score pada penggunaan 106 ciri ini adalah 98,76\% dan 98,01\%. Berdasarkan nilai F1-score, penggunaan 124 ciri pada pengenalan batik berdasarkan motif mendapatkan hasil yang lebih baik jika dibandingkan dengan 106 ciri. 


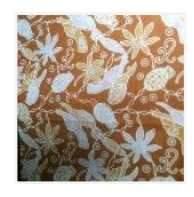

(a)

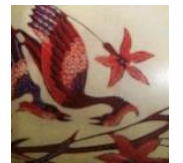

(b)

\section{Gambar 10. Contoh kelas yang salah diklasifikasi: (a) Pusdik_Kombinasi, (b) Bango_Rawa}

Gambar 10 merupakan contoh citra yang salah diklasifikasi pada pengenalan citra berdasar motif. Dua kelas tersebut, yaitu kelas motif Pusdik-kombinasi dan kelas motif Bango-Rawa merupakan kelas yang salah diklasifikasikan satu sama lain.

\section{KESIMPULAN}

Pada artikel ini dipaparkan hasil pengenalan batik dalam jumlah kelas yang besar, yaitu 114 kelas, yang berasal dari 114 motif batik. Citra batik yang digunakan merepresentasikan batik dari 14 daerah di propinsi Jawa Barat. Ciri tekstur dan warna digabungkan untuk mendapatkan ciri gabungan dengan menggunakan metode Gray Level Cooccurrence Matrix (GLCM) dan Color Difference Histogram (CDH). Dengan Support Vector Machine (SVM) sebagai classifier, vektor ciri gabungan yang berdimensi 124 terbukti menghasilkan akurasi yang lebih baik dibandingkan dengan vektor ciri berdimensi 106, dengan nilai F1-score sebesar $98,32 \%$.

\section{DAFTAR PUSTAKA}

[1] Ministry of Culture and Tourismin collaboration with UNESCO Office, Practical handbook for inventory of intangible cultural heritage of Indonesia. Ministry of Culture and Tourism of the Republic of Indonesia, 2009.

[2] A. E. Minarno and N. Suciati, "Batik Image Retrieval Based on Color Difference Histogram and Gray Level Co-Occurrence Matrix," TELKOMNIKA (Telecommunication Comput. Electron. Control., vol. 12, no. 3, p. 597, 2014.

[3] A. E. Minarno, A. S. Maulani, A. Kurniawardhani, F. Bimantoro, and N. Suciati, "Comparison of methods for Batik classification using multi texton histogram," Telkomnika (Telecommunication Comput. Electron. Control., vol. 16, no. 3, pp. 1358-1366, 2018.

[4] S. Sunawar, "Klasifikasi Motif Batik Menggunakan Metode Ekstraksi Gray Level Co-Occurence Matrix ( GLCM ) Pada Platform Android," Universitas Muhammadiyah Malang, 2017.

[5] Y. Gultom, A. M. Arymurthy, and R. J. Masikome, "Batik Classification using Deep Convolutional Network Transfer Learning," J. IImu Komput. dan Inf., vol. 11, no. 2, p. 59, 2018.

[6] A. Y. Wicaksono, N. Suciati, C. Fatichah, K. Uchimura, and G. Koutaki, "Modified Convolutional Neural Network Architecture for Batik Motif Image Classification," IPTEK J. Sci., vol. 2, no. 2, pp. 26-30, 2017.

[7] A. E. Minarno, Y. Azhar, F. D. Setiawan Sumadi, and Y. Munarko, "A Robust Batik Image Classification using Multi Texton Co-Occurrence Descriptor and Support Vector Machine," in 2020 3rd International Conference on Intelligent Autonomous Systems (IColAS), 2020, pp. 51-55.

[8] M. Sholihin, "Classification of Batik Lamongan Based on Features of Color, Texture and Shape," Kursor, vol. 9, no. 1, pp. 25-32, 2018.

[9] R. Fahrizal, R. P. Parlindungan Siahaan, and R. Wiryadinata, "Banten batik classification with backpropagation neural network," in MATEC Web of Conferences, 2018, vol. 218, pp. 1-9.

[10] R. Andrian, M. A. Naufal, B. Hermanto, A. Junaidi, and F. R. Lumbanraja, "K-Nearest Neighbor (k-NN) Classification for Recognition of the Batik Lampung Motifs," J. Phys. Conf. Ser., vol. 1338, no. 1, 2019.

[11] M. A. Rasyidi and T. Bariyah, "Batik pattern recognition using convolutional neural network," Bull. Electr. Eng. Informatics, vol. 9, no. 4, pp. 1430-1437, 2020.

[12] X. Zhang, Y.-H. Yang, Z. Han, H. Wang, and C. Gao, "Object class detection: a survey," ACM Comput. Surv., vol. 46, no. 1, pp. 1-53, 2013.

[13] R. M. Haralick, K. Shanmugam, and I. Dinstein, "Textural features for image classification," IEEE Trans. Syst. Man. Cybern., vol. SMC-3, no. 6, pp. 610-621, 1973.

[14] M. Hall-Beyer, GLCM Texture: a Tutorial, vol. 2, no. March. 2017.

[15] S. Di Zenzo, "A note on the gradient of a multi-image," Comput. Vision, Graph. Image Process., vol. 33, no. 
1, pp. 116-125, 1986.

[16] M. Sokolova, N. Japkowicz, and S. Szpakowicz, "Beyond Accuracy, F-score and ROC: a Family of Discriminant Measures for Performance Evaluation," in Australian Joint Conference on Artificial Intelligence Al 2006: Advances in Artificial Intelligence, 2006, no. c, pp. 1015-1021.

[17] S. K. Atik, Buku Saku Batik Jawa Barat Jilid 2. Yayasan Batik Jawa Barat (YBJB), 2014.

[18] S. Borra and A. Di Ciaccio, "Measuring the Prediction Error. A Comparison of Cross-Validation, Bootstrap and Covariance Penalty Methods," Comput. Stat. Data Anal., vol. 54, no. 12, pp. 2976-2989, Dec. 2010.

Lampiran: contoh citra dari 114 kelas motif
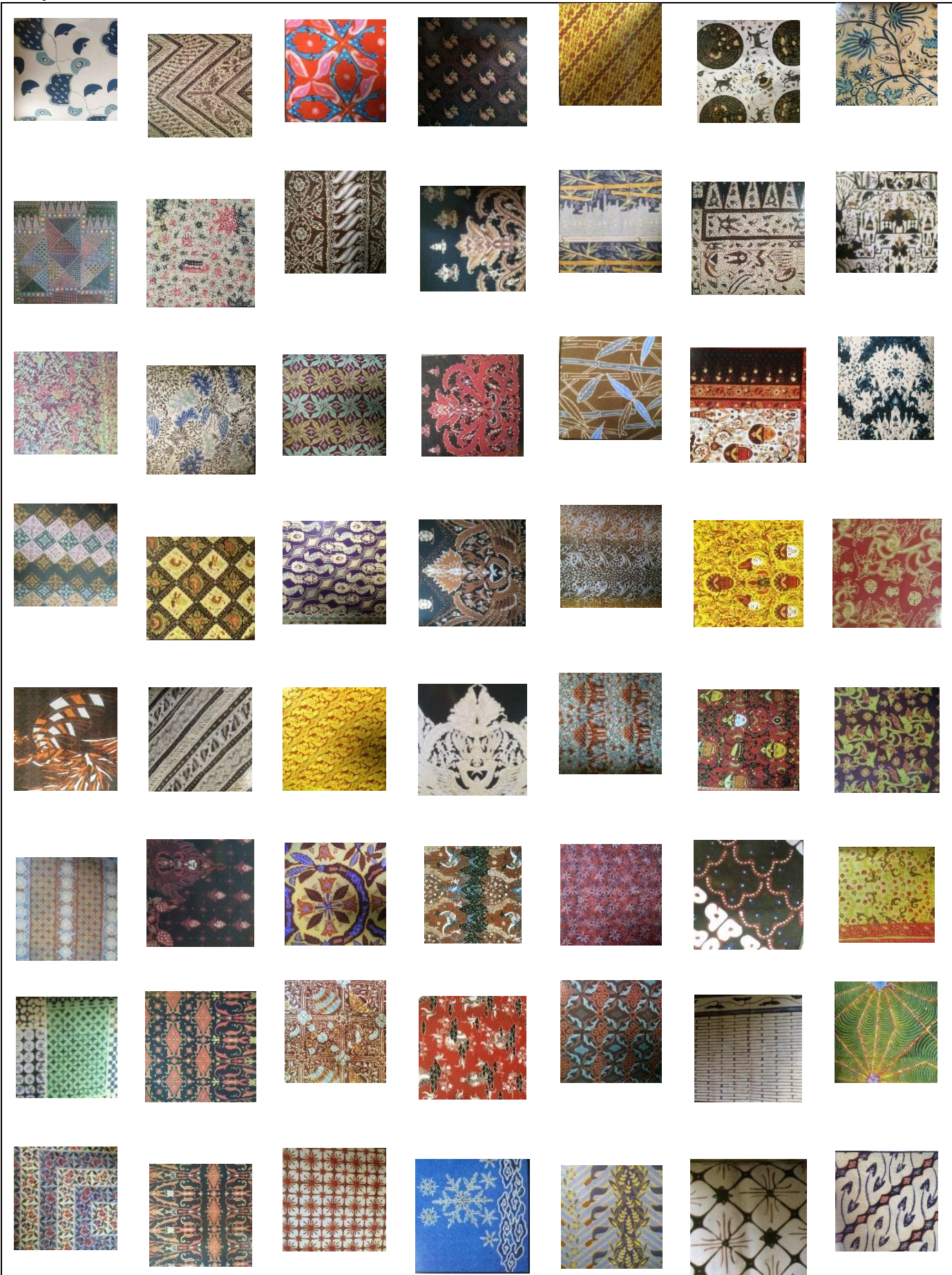


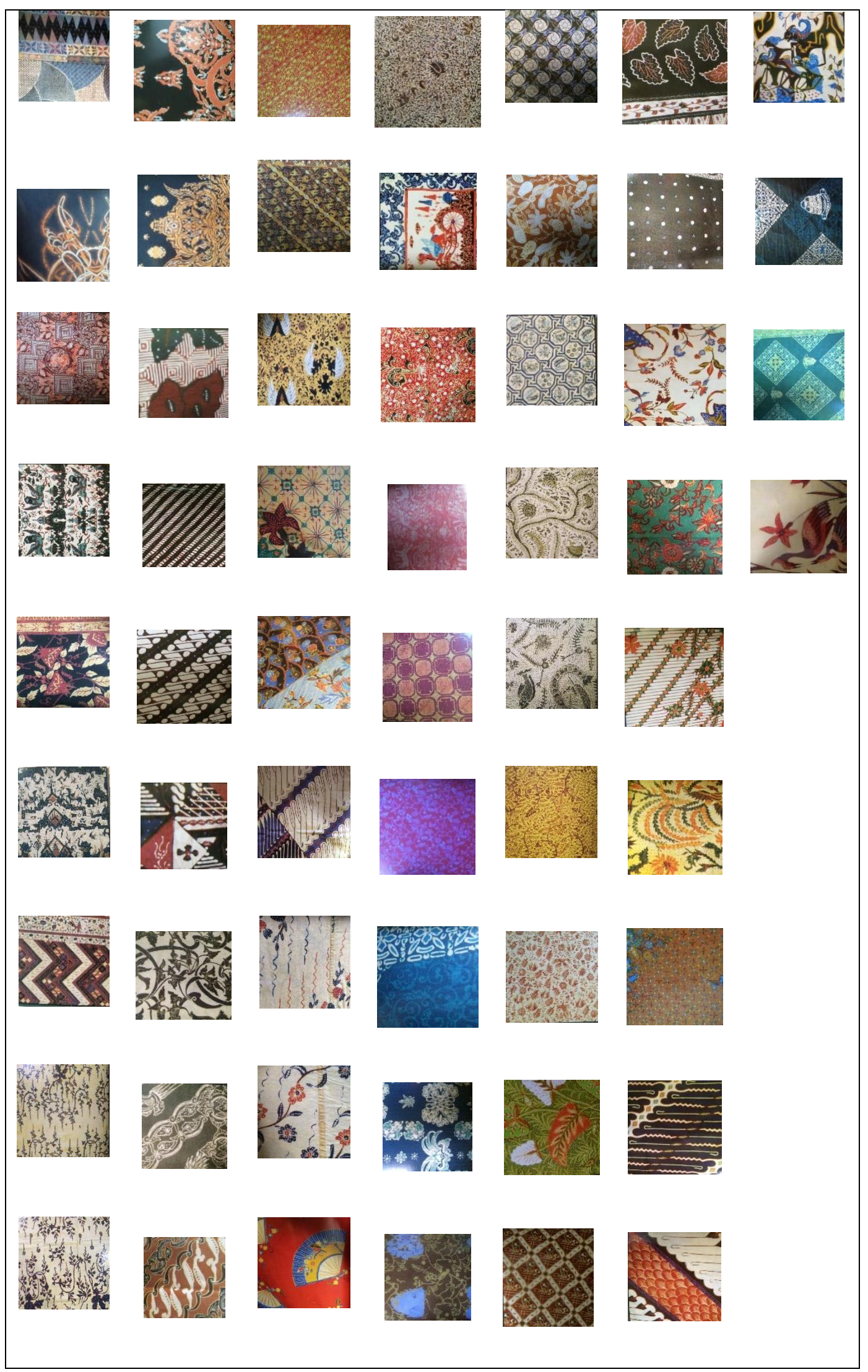

